\title{
Participatory Agricultural Humanities for the new Ruralism Tea-Community Revitalization In Taiwan
}

\author{
Shenglin Elijah Chang ${ }^{* 1}$, Ze-jyun Yang ${ }^{2}$, Ming-yang Kuo ${ }^{3}$, Ting-hsiun Hsiao 4 \\ ${ }^{1}$ Graduate Institute of Building and Planning, No. 1, Sec. 4, Roosevelt Road, Taipei 106, Taiwan
}

\begin{abstract}
This paper examines the most effective ways of engaging urban citizens to appreciate rural villages and agriculture traditions. Pondering on experiences of rural revitalization experiments in Asian societies, this paper proposes the concept of "participatory agricultural humanities." Participatory agricultural humanities are tools and processes engaging citizens into eco-friendly farming and land related works or events. Based on action research and qualitative research methods, we have been working with periurban and rural communities in Taiwan since 2009. Only embracing agricultural humanities as our values, we could re-establish eco-friendly rural developments with biodiversity and cultural diversity as a whole.
\end{abstract}

(C) 2016. The Authors. Published for AMER ABRA by e-International Publishing House, Ltd., UK. This is an open access article under the CC BY-NC-ND license (http://creativecommons.org/licenses/by-nc-nd/4.0/).

Peer-review under responsibility of AMER (Association of Malaysian Environment-Behaviour Researchers), ABRA (Association of Behavioural Researchers on Asians) and cE-Bs (Centre for Environment-Behaviour Studies), Faculty of Architecture, Planning \& Surveying, Universiti Teknologi MARA, Malaysia.

Keywords: agricultural humanities, rural revitalization, participation, new ruralism

\section{Introduction: Human paths from rural to urban}

Agriculture has been the single most significant root of civilizations in human history. Unfortunately, the capitalization in the modern time has been cutting our agro-root in our daily life. Meanwhile, since the raising of the agricultural industry, the majority of the modern citizens have seldom planted one's food and touched the soil. Farming has turned into a professional occupation that a small group of agro-laborers is in charge.( Altieri 1989 \& 2002) Rural declines and depressions have been deeply relating to the "agri-industry" and WTO in the twentieth century. To rebuild and revitalize depressed rural areas, we have to re-search for "agri-culture", the so-called agricultural humanities that I proposed here.

\footnotetext{
${ }^{*}$ Corresponding author. Tel.:

E-mail address: shenglinchang@gmail.com
}

2398-4287 @ 2016. The Authors. Published for AMER ABRA by e-International Publishing House, Ltd., UK. This is an open access article under the CC BY-NC-ND license (http://creativecommons.org/licenses/by-nc-nd/4.0/).

Peer-review under responsibility of AMER (Association of Malaysian Environment-Behaviour Researchers), ABRA (Association of Behavioural Researchers on Asians) and cE-Bs (Centre for Environment-Behaviour Studies), Faculty of Architecture, Planning \& Surveying, Universiti Teknologi MARA, Malaysia.

DOI: http://dx.doi.org/10.21834/e-bpj.v1i3.369 
What are the most effective ways of engaging urban citizens to appreciate rural villages and agriculture traditions? Pondering on my experiences of rural revitalization experiments in Taiwan, Japan, and China, and other societies, I propose the concept of "participatory agricultural humanities." Participatory agricultural humanities refer to agricultural practices, cultivations, and innovations embodying social, environmental and ethical aspects rooted in histories and civilizations. Participatory agricultural humanities are tools and processes engaging citizens into ecofriendly farming and land related works or events. The tools usually apply to urban citizens or people without too much farming experiences. Recently, our human world has been facing the food shortage, climate changes, and energy crisis in the 21st century. People, especially those who reside in cosmopolitans, need to re-connect to agriculture to save the environment. Only embracing agricultural humanities as our values, we could re-establish eco-friendly rural developments with biodiversity and cultural diversity as a whole.

\section{Background of agricultural and civilization}

Indeed, we shall adjust our twenty-century ideas of urban landscapes and lifestyles when more than a half of our population has moved into urbanized areas in the dawn of the 21 st century. It is the first time in human history the majority of human beings on earth habit in places away from farms, forests, rivers, and animals. We, humans, may be safe from being attacked by beasts, on the one hand. On the other hand, we are away from trees, flowers, and food supplies that we need daily. Even worse, during the 2008 world food crisis, urban dwellers suddenly realized that their everyday groceries and basic agri-supplies on kitchen tables are hundreds of miles away from their city homes. More importantly, the food crisis combined with the raising price of oil lead to the Arab revolutions. The riots first started Tunisia, then to Egypt, Haiti, Pakistan and other countries. Aside of the political and economic injustice within these countries, the lack of food accessibility for the majority of urban poor was certainly the core of the crisis. Integrating edible landscape with the urban planning systems has been more and more critical for mega cities around the world. Large cities, i.e., Philadelphia, have been already promoting the food system planning in their blue prints of resilient city schemes. In London's Capital Growth campaign 2012, the city targets to develop 2012 new pieces urban agricultural lands by the year of 2012. Paris, Tokyo, New York, and many other cities have been engaging in various agricultural activities, including community gardens, roof gardens, bee farms, food banks, and so on.

Agriculture is more than a way of production. It is a lifestyle. Urban dwellers also seek for the possibility of alternative urban-agri lifestyles. "Farming under sunrise, resting after dark" (日出而作，日末而息) has been an agri-life paradigm shared by people with Chinese agricultural heritages before the rapid industrialization and massive urbanization since the mid twenty century. This agri-life paradigm is also valued by many other civilizations in the past because it is a way of life that people support their needs with what they grow from their yards. In agricultural time, cultivating one's food for one's family or self was a default lifestyle for the majority residing in rural towns and villages outside cities. Only small portion of people who dwelled in urban areas might take on jobs other than farming. In other words, we can argue, within thousands of years of human history, most of our ancestors and elderly in our families, live in the lifestyle of "farming under sunrise, resting after dark." Working in a particular type of jobs without nurturing one's food is a contemporary lifestyle evolving with the birth of urban growth for only about half century long.

Within the less than hundred years long urbanizing period, urban agriculture has always been one of the key mechanisms to revitalize the local economy and food supplies during wars, oil crisis, and economic depressions. Piles of research have demonstrated the significant physical and socio-psychological contributions that urban agriculture has done for city dwellers. However, plots and patches for planting vegetables or feed animals in urban neighborhoods were seldom legally defined. Even worse, unlike the Capital Growth campaign targeting to get 2012 new urban edible lands by the year of 2012 in London, the action of planting edible landscape was considered illegal in a large portion of urban Taiwan until 2015. In the case of the capital city Taipei, by law, planting fruit trees and vegetables in parks and public spaces is forbidden. In the case of Gao-Xiong, a group of eight retired elderly cultivated their vegetable garden on a vacant lot for several years. One day (August 23, 2011), they were called by the local court and sued for the unauthorized use of the state's property because of developing their personal 
garden patches. "We were taking care of the vacant land, removing weeds, and guarding the place against drugs and crimes. Why the State Government sues us?" One senior expressed his feeling and depressed. Neighbors were also surprised by the situation. "Why could not allow granddaddies and grandmas do gardening exercises in the vacant lot?" One neighbor asked.

\section{Processes of agricultural humanities}

Upon this backdrop of human urbanization history, we urgently call for actions to bring the agricultural roots back to citizens' everyday life. Within this line of thinking, we develop the participatory process to engage citizens in farming related labor work, and we named it, participatory agricultural humanities. The purpose of participatory agricultural humanities is not about farming per se, but about evolves personal values of agriculture during the working process.

To practice agricultural humanities, we have been developing action research processes to experiment participatory methods in towns and rural regions with students and professors from different universities. Upon now, we have formed semi-structured open-ending procedures list as follow:

\section{Processes}

During participatory farming engagements, urban citizens engender their ecological value systems support biodiversity and sensitive environmental revitalizations for rural community planning and developments. The stepby-step instructions are loosely listed below:

1. Targeting accessible depressing rural communities

Peri-urban areas are the best locations for urban citizens to access. As long as there are opportunities to farm, citizens would be able to experience how their urban bodies re-bond with the earth. However, towns and communities with distinctive farming styles and culturally based cultivations would work the best.

2. Searching for active eco-farmers' networks and potential lands

Building up partnerships with local eco-farmers and establishing networks are the second steps. To setting up participating farming programs or eco-farming tours, we need to collaborate with a few local eco-farmers. More importantly, we shall identify potential garden patches or land pieces for farming.

3. Planning and preparing eco-friendly ways to engaging people (tours or events)

Based on types of crops and seasons, we plan participatory eco-farming events, or tours to engage city folks. Participatory farming aims to educate city folks the ecological values and to engage them in eco-agricultural chains, from nurturing crops, to marketing products, to revitalizing rural towns and communities.

4. Story telling via social media to cultivate agricultural humanities

The fourth step is an open-ending process: storytelling via social media. We encourage these urban participants sharing their farming pictures, stories, and reflections on their Facebook, Line, Twitter, and other internet social network services. By sharing their stories, these personal stories and experiences could also promote depressed rural communities and help market local agricultural products.

\section{Tea farming for experimenting agricultural humanities}

Located in the northeast corner of Taiwan, Pinglin Township features a population of 6,000 living in an area of 170 square kilometers on the outskirts of Taipei. It is the site of Feitsui Reservoir, the primary source of drinking water for six million people living in the Taipei basin. Restrictions on land use within the water protection zone leave tea farming and small industry as the only means for residents to make the living, so younger residents prefer to 
relocate to Taipei to pursue urban white-collar careers. Also, for the past two decades, the local market for tea products has been saturated by cheap tea imported from Vietnam dramatically damaging the viability of local teas. More importantly, Taiwan nation-wide tea competitions have profoundly transformed tea farming and baking craftsmanship. (Lin 2012) Also, the completion of a highway tunnel has routed potential tourist traffic away from Pinglin. Due to these factors, local economic performance sharply declined.(Hsiao 2013)

To address the serious economic and environmental issues presented in Pinglin, my team (students and faculty of the Graduate Institute of Building and Planning at National Taiwan University, henceforth BP-NTU), initiated the participatory tea farming project (including, Blue Magpie Tea and Sapuku Tea) that seeks to promote the healthy food and water and quality of life, targeting transformations of Pinglin's rural development.(Chang 2013, Chen \& Chang 2015) Since 2011 winter, my team have been innovating the concept of "participatory agricultural humanities" and experimenting various eco-tea actions to engaging metropolitan residents of Taipei to visit the Pinglin Tea town.

Turning urban consumers to be partners with towns and rural communities via participatory agricultural actions is the key that my team found very effective. In the case of Pinglin, we have been brought hundreds of urban families, professionals, students, and café owners to this depressed tea town to support eco-friendly tea farming. (Chang 2013) By participating tea framing works, tea leaves pickings, and tea makings, these urban folks have been aware of difficulties of eco-farming as well as the beauty of natural tea plantations. They self-motivated support eco-friendly tea brandings and rural revitalizations in their ways (Figure 1). Some of them bring their friends and families to these depressing towns; others provide their professional talents to support local educational needs or services.

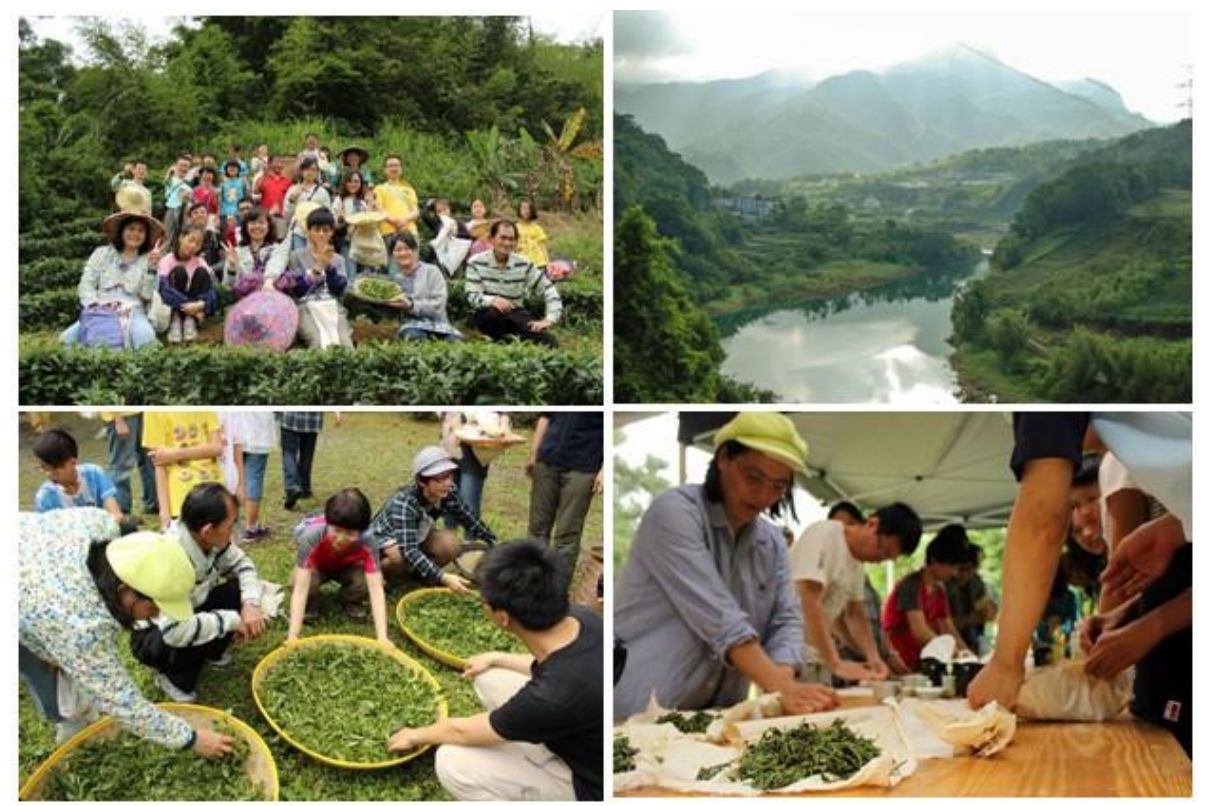

Figure 1: Pinglin Tea town locates at the upstream of the Feitsui Reservoir. We have been innovating the participatory tea actions to connect urban consumers with the tea plantations and initiate the rural revitalizations.

(Photo taken by the Sanpuku team)

Based on the participatory tea actions we apply in Pinglin Tea town, we have been evolving three stages from 2012 to present:

1. Empowering declined the Pinglin Tea town

Second-generation tea farmers returning and initiating their networks; after-school programs for tea farmers' children operating

2. Establishing social enterprises

Establishing two social enterprises of the tea cultural based companies, two more in preparation 
3. Engaging the National Taiwan University

Structuring Agricultural Humanities curriculum to sustain university participations in Pinglin and other areas (Together, 50 more professors and instructors joined and about 30 classes organized)

\section{Conclusion}

My case and methods examine how the participatory agriculture in the peri-urban New Taipei City could function as catalysts that connect urban consumers with agricultural humanities and stimulate rural revitalization (Figure 2).

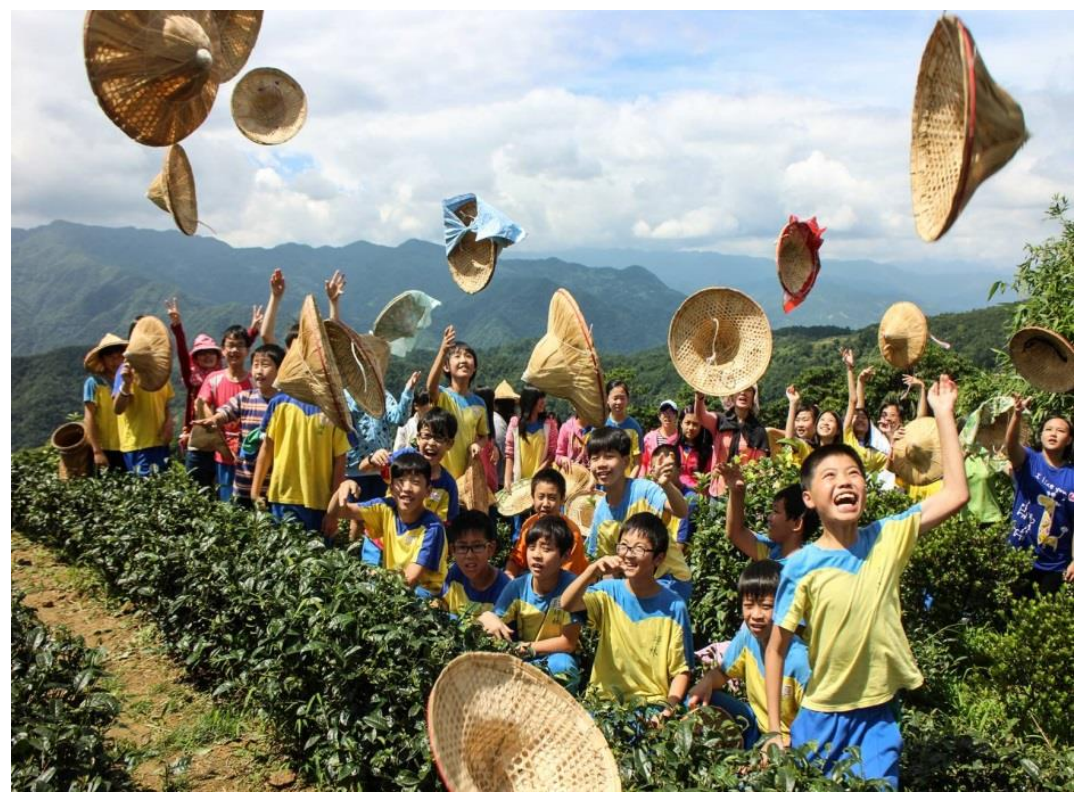

Figure 2: One primary goal of participatory agricultural humanities is to nurture local pride of the incoming rural young generations. As a part of the Pinglin Elementary School commencement, my team structured a participatory tea making event that engaged local students. None of their parents were tea farmers, but worked in urban areas. It is critical to bring rural youth back to their home landscape.

(Photo was taken by Mingyang Kou)

Participatory agricultural humanities strive to: (1) to re-connect and re-balance urban and rural through ecological engagements and (2) to nurture local pride of the incoming rural young generations. Ultimately, we attempt to re-plant agri-culture in the contemporary urbanism civilization. It takes team efforts and long-term commitments to achieve this humble but extraordinary goal.

\section{Acknowledgements}

This contribution was funded by the National Science Council (102-2410-H-002 -158 -MY2). Research assistants include Ren-zhi Huang, ZeJun Young, and Ming-yang Kou.

\section{References}

Altieri, M. A. (1989). Agroecology: A New Research and Development Paradigm for World Agriculture. Agriculture, Ecosystems and Environment, 
$27,37-46$.

Altieri, M. A. (2002). Agroecology: the science of natural resource management for poor farmers in marginal environments. Agriculture, Ecosystems and Environment, 93, 1-24.

Chang, S. E. (2013). Blue Magpie TEAgriculture: Eco-tea Cultivation and Participatory Farming in Pinglin Satoyama, Taiwan. Procedia - Social and Behavioral Sciences, 101, 14-22.

Chen, L.-c., Chang S. E. (2015) Building and Recovering Rural Economic Landscapes: The Case of Liquor and Tea Industries in Taiwan. Procedia - Social and Behavioral Sciences, 202, 408-416.

Hsiao, D.-h. (2013) From Cultural and Creative Gilded to Moral Economic - The Action of Pinglin Taiwan Blue Magpie Tea. Master Thesis: National Taiwan University.

Lin, W.-k. (2012). The effect of tea tasting contest in developing local tea industry: a case study of wenshan baozhong tea. Master Thesis, National Taiwan University. 